\title{
Narciso M. Machado, Afonso Henriques: Data e local do seu nascimento
}

\section{Abel Estefânio}

\section{(2) OpenEdition}

1 Journals

\section{Edição electrónica}

URL: http://journals.openedition.org/medievalista/1292

DOI: 10.4000/medievalista.1292

ISSN: 1646-740X

\section{Editora}

Instituto de Estudos Medievais - FCSH-UNL

\section{Refêrencia eletrónica}

Abel Estefânio, « Narciso M. Machado, Afonso Henriques: Data e local do seu nascimento », Medievalista [Online], 21 | 2017, posto online no dia 01 junho 2017, consultado o 23 setembro 2020. URL : http://journals.openedition.org/medievalista/1292 ; DOI : https://doi.org/10.4000/medievalista. 1292

\section{(c) () \&}

Mediavalista está licenciado com uma Licença Creative Commons - Atribuição-NãoComercial 4.0 Internacional 
Título / Title: Recensão: MACHADO, Narciso M. - Afonso Henriques: Data e local do seu nascimento. Edição do autor: Braga, 2016 (154 pp.)

Autor(es) / Author(s): Abel Estefânio

Universidade / University: Investigador independente

Faculdade e Departamento / Unidade de Investigação - Faculty and Department /

Research Center: N/A

Código Postal / Postcode: 4000-266

Cidade / City: Porto

País / Country: Portugal

Email Institucional / Institutional email: aestefanio@hotmail.com

Fonte: Medievalista [Em linha]. Direc. Bernardo Vasconcelos e Sousa. Lisboa: IEM.

Disponível em:

http://www2.fcsh.unl.pt/iem/medievalista/MEDIEVALISTA21/estefanio2108.html

ISSN: 1646-740X

Data de recepção do texto / Received for publication: 25 de Julho de 2016 


\title{
Recensão: MACHADO, Narciso M. - Afonso Henriques: Data e local do seu nascimento. Edição do autor: Braga, 2016 (154 pp.)
}

\author{
Abel Estefânio
}

Onde nasceu o primeiro rei de Portugal? Este tema clássico da História Medieval Portuguesa tem despertado regularmente o interesse dos investigadores. Uma tradição culta, remontando ao século XV e que se cimentou nos séculos que se seguiram, colocava o nascimento em Guimarães. Todavia, na segunda metade do século XX, surgiu uma opinião no meio universitário a colocar o nascimento de Afonso Henriques em Coimbra. A questão tem sido especialmente debatida nos últimos vinte e cinco anos, para o que contribuiu o surgimento de uma terceira possibilidade, o nascimento em Viseu, de acordo com uma tese de A. de Almeida Fernandes. O seu trabalho foi pela primeira vez publicado na Revista Beira Alta, entre 1990 e 1991, e em edição autónoma, em 1993, pelo Governo Civil do Distrito de Viseu, com o título Viseu, Agosto de 1109, nasce D. Afonso Henriques, sendo reeditado pela SACRE / Fundação Mariana Seixas, em 2007.

Esta tese seria subscrita “oficiosamente” por Manuela Mendonça, presidente da Academia Portuguesa da História, no primeiro livro da coleção Reis de Portugal de que é autora ${ }^{1}$ e aceite como plausível por um número significativo de historiadores, apesar de o problema ainda estar longe de uma solução definitiva, quer quanto à data, quer quanto ao local. Disso mesmo procurei dar conta em dois artigos publicado na revista

\footnotetext{
${ }^{1}$ MENDONÇA, Manuela - D. Afonso Henriques: o conquistador 1143-1185. Lisboa: QuidNovi, 2009.
} 
Medievalista online: "A data de nascimento de Afonso I" $\mathrm{e}$ "De novo a data e local de nascimento de Afonso I"3.

O livro que ora recenseamos é um trabalho de um vimaranense que expressa a reação sentimental de uma comunidade que viu ameaçada a "tradição" do nascimento do nosso primeiro rei em Guimarães. A discussão do tema nem sempre foi edificante. O excesso de crítica e de polémica conduziu algumas vezes ao achincalhamento ou mesmo insulto entre intervenientes situados em lados diferentes da barricada, com alguns danos colaterais em quem não estava interessado na contenda. Convém esclarecer que isso não se aplica ao juiz desembargador Narciso Marques Machado, disposto a assumir o seu bairrismo de uma forma serena, sadia e edificante, fornecendo à discussão contribuições valiosas que importa sublinhar.

O juiz desembargador, jubilado desde 2007, tem dedicado muito do seu tempo à investigação histórica vimaranense, sobretudo da época romana e medieval. Entre outros títulos publicados, refira-se Os 900 anos do nascimento de D. Afonso Henriques (2009), Rede viária romana e medieval do concelho de Guimarães (2012), Processo de beatificação de D. Afonso Henriques (2014) e A batalha de S. Mamede (2015). Não posso deixar de registar a afinidade com o autor desta nota, no que se refere à persistência com que aborda o tema do nascimento do primeiro rei, ao longo dos últimos anos.

Ainda antes de abrir o livro, merece a pena determo-nos na apreciação da capa, que contém uma imagem da pintura do batismo de D. Afonso Henriques por S. Geraldo, arcebispo de Braga, do pintor Simão Álvares, vimaranense de evocação nacionalista, com atividade conhecida entre 1638 e 1657. Cronologicamente, a execução do quadro antecedeu a inscrição mandada fazer, em 1664, pelo prior da Colegiada de Nossa

\footnotetext{
${ }^{2}$ ESTEFÂNIO, Abel - "A data de nascimento de Afonso I”. Medievalista 8, (Julho de 2010). [Em linha]. Disponível em http://www2.fcsh.unl.pt/iem/medievalista/MEDIEVALISTA8lestefanio8002.html ${ }^{3}$ ESTEFÂNIO, Abel - "De novo a data e o local de nascimento de Afonso I". Medievalista 19 (Janeiro Junho 2016). [Em linha]. Disponível em http://www2.fcsh.unl.pt/iem/medievalista/MEDIEVALISTA19/estefanio1906.html
} 
Senhora da Oliveira, D. Diogo Lobo da Silveira, que se encontra atualmente colocada junto da pia batismal da capela de S. Miguel do Castelo, em Guimarães, com os seguintes dizeres "Nesta pia foi batizado el-rey dom Afonso Henriques pelo arcebispo de Braga S. Geraldo, ano do Senhor de 1106". Vivia-se então em plena Guerra da Restauração, que cremos poder estar na base da necessidade de recuperação dos mitos da "portugalidade" e Guimarães parece ter tido um papel preponderante nesse contexto.

Passando ao conteúdo do livro, poderemos encontrar aí a solução definitiva do problema? É esse o juízo do autor do prefácio, A. Martins Vieira, que conclui que Narciso Machado "não necessita de fazer mais pesquisas, gastar mais tinta, mais papel, porque, neste livro, já disse tudo sobre quando nasceu e onde nasceu o nosso primeiro rei, Afonso Henriques".

Vejamos então o texto, nos aspetos que consideramos mais relevantes para a questão em causa. Narciso Machado começa por enquadrar cronologicamente que o conde D. Henrique sucedia, por nomeação régia, aos antigos condes de Portucale, sediados em Guimarães. Juntado esse facto à "tradição" vimaranense, a identificação do local de nascimento é dada como pressuposto de toda análise que se segue.

Dedicando a sua atenção à data de nascimento, começa por conjugar a informação da Chronica Gothorum - de que Afonso Henriques teria dois ou três anos quando o pai morreu - com a dos dois documentos da doação do mosteiro do Lorvão à Sé de Coimbra, datados de 29 de julho de 1109, para os quais apresenta a transcrição latina e a respetiva tradução para português.

Narciso Machado põe então a descoberto algumas das fragilidades da tese de Almeida Fernandes, nomeadamente a falta de justificação quanto ao número de dias ocorrido entre as duas cerimónias e quanto à admissibilidade do pressuposto de ausência de D. Teresa na cerimónia super altare na Sé de Coimbra, por se encontrar no final do tempo de gravidez em Viseu. Na verdade, a infanta confirma ambos os documentos e também 
não se pode afirmar com segurança que Afonso Henriques tenha nascido por essa ocasião.

Dando relevo ao facto de os documentos mencionarem os filhos e filhas dos condes, $\mathrm{N}$. Machado conclui que Afonso Henriques seria um dos filhos aludidos. Poder-se-ia objetar que a referência aos filhos seria uma mera "fórmula de chancelaria". Não nos parece ser esse o caso, dado que não consta na escritura de doação do Mosteiro de São Vicente da Vacariça à Sé de Coimbra, que lhe serviu de modelo.

Pelo meio, uma outra crítica certeira a A. Fernandes, por ter colocado, sem apresentar justificação, o foral de Azurara da Beira em agosto de 1109, de forma a favorecer a sua tese, quando a data crítica apontada pelo diplomatista Rui Pinto de Azevedo, estabeleceu o intervalo entre os anos de 1109 e 1112. O juiz desembargador conclui, tirando proveito da sua especialização jurídica, que "tudo isto dá a ideia de que D. Henrique e D. Teresa não tinham poder de marcação das atos documentais em que ambos eram outorgantes".

Fazendo referência a um documento de Oviedo de 25 de abril de 1109, N. Machado admite que o nascimento do rei fundador teria de ter ocorrido em Guimarães, nos primeiros três meses desse ano. Esse documento, citado de Marsilio Cassotti ${ }^{4}$ induz erradamente o autor que o conde e a infanta teriam seguido então para Oviedo, quando uma análise mais atenta à fonte impressa citada mas seguramente não consultada ${ }^{5}$ permitiria concluir que D. Henrique e D. Teresa apenas foram referidos no documento por serem os tenentes de Tinegio (Tineo, nas Astúrias), logo a seguir à menção de D. Afonso VI e D. Beatriz como reis de Toledo e Leão, não participando uns e outros como outorgantes ou confirmantes, pelo que não se pode concluir pela sua presença física no ato. Mas, mesmo que aceitássemos essa hipótese, também não se podia

\footnotetext{
${ }^{4}$ CASSOTTI, Marsilio - D. Teresa. A primeira rainha de Portugal. Lisboa: A Esfera dos Livros, 2008, p. 107.

${ }^{5}$ COLECCIÓN de documentos de la Catedral de Oviedo. Ed. Santos García Larragueta. Oviedo: Instituto de Estudios Asturianos, 1962, pp. 339-341.
}

Medievalista online $^{\circ} 21 \mid$ Janeiro - Junho 2017 ๑ IEM - Instituto de Estudos Medievais 5 www2.fcsh.unl.pt/iem/medievalista 
concluir que tivessem partido de Guimarães, donde não há notícia dos condes posterior a 11 de Julho de 1103, data em que são beneficiários de uma doação de bens situados neste concelho. Por outro lado, entre essas duas datas, encontramos o conde D. Henrique a outorgar ou confirmar mais de três dezenas de documentos leoneses, entre documentos régios e particulares, sendo alguns deles em companhia de D. Teresa, pelo que não existem indícios que nos levem a concluir que tivessem residência habitual em Guimarães, pelo menos nesse período.

De seguida, N. Machado acolhe a conclusão do meu primeiro artigo publicado na Medievalista OnLine, que passa por considerar a Vita Theotonii como a fonte mais credível sobre a data de nascimento de Afonso Henriques, em detrimento da Chronica Gothorum. Recorde-se que aquela diverge desta, por colocar o nascimento mais cedo, em torno de 1106. Atente-se que ao privilegiar agora uma fonte diferente, não transparece qualquer preocupação sobre o impacto que a mudança de data poderia ter relativamente à averiguação do local de nascimento.

Nas escassas nove páginas que constituem o capítulo dedicado ao local de nascimento, são apresentados nove "argumentos" que parecem não convencer o próprio autor da compilação, o que o leva a concluir que "na dúvida perante esses documentos, resta-nos continuar a acreditar na tradição", ou seja, de que Afonso Henriques nasceu no palácio real de Guimarães. É certo que os historiadores, na sua generalidade, consideraram até ao presente que os condes viveram normalmente em Guimarães. No meu mais recente artigo publicado na Medievalista OnLine, creio ter feito uma demonstração rigorosa do contrário, fazendo uso da documentação leonesa como até aqui nunca tinha sido devidamente aproveitada, para estabelecer os itinerários de D. Henrique e de D. Teresa.

A título de epílogo, devo dizer que não me surpreenderá que Narciso Machado, ao tomar conhecimento do meu estudo depois da publicação da sua obra, não reveja a sua posição quanto ao local de nascimento, como fez anteriormente quando leu o meu primeiro artigo relativamente à data, fazendo assim jus ao vaticínio do prefaciador. A razão é simples e está subordinada à ligação afetiva entre a comunidade a que pertence e 
o fundador da nacionalidade. Ao colocarmos objeções à data de nascimento aceite por Almeida Fernandes para o desenvolvimento da tese visiense, elas poderiam ser aproveitadas para favorecer a tradição vimaranense. Ao propormos agora, como possível, o nascimento de Afonso Henriques fora do Condado Portucalense, não alimentamos a disputa entre essas cidades. Gostaríamos, sim, de contribuir para a sua união na celebração do essencial: D. Afonso Henriques fundou Portugal.

\section{COMO CITAR ESTE ARTIGO}

\section{Referência electrónica:}

ESTEFÂNIO, Abel - “Recensão: MACHADO, Narciso M. - Afonso Henriques: Data e local do seu nascimento. Edição do autor: Braga, 2016 (154pp.)”. Medievalista 21 (Janeiro-Junho 2017). [Em linha] [Consultado dd.mm.aaaa]. Disponível em http://www2.fcsh.unl.pt/iem/medievalista/MEDIEVALISTA21/estefanio2108.html ISSN 1646-740X.

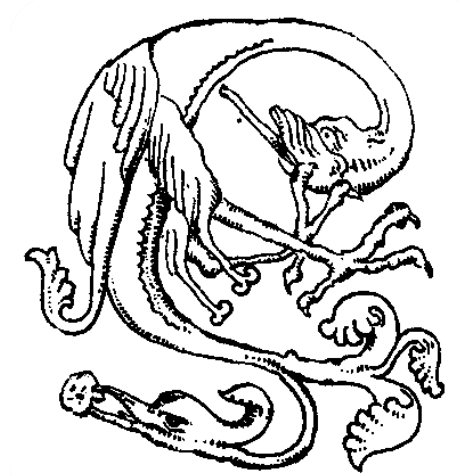

